\title{
Study on W Company's Green Supplier Selection
}

\author{
Hongqi Hui \\ School of Economics and Management \\ Hebei University of Science and Technology \\ Shijiazhuang, China
}

\author{
Xin Wang \\ School of Economics and Management \\ Hebei University of Science and Technology \\ Shijiazhuang, China
}

\begin{abstract}
In the face of the uncertainty of green supplier selection, this paper uses the Analytic Hierarchy Process (AHP) and Ideal Point Method (TOPSIS) to judge the model and construct a comprehensive evaluation index system. To optimize the practice research of $W$ company, select the most suitable green supplier, and propose relevant countermeasures to promote the development of green supplier selection evaluation model.
\end{abstract}

Keywords-green supplier; analytic hierarchy process; ideal point method; comprehensive evaluation

\section{INTRODUCTION}

Under the current situation of increasing shortage of social resources and increasingly serious environmental pollution, enterprises should also consider social benefits while considering economic benefits. Moreover, achieving environmentally-friendly development is an important means to seize the opportunities of development and enable enterprises to obtain A greater competitive advantage. Therefore, in order to balance the relationship between the economy and the environment, it is necessary to select green suppliers and establish a scientific and effective green supplier selection evaluation model.

Researchers at home and abroad have proposed various solutions to solve the problem of green supplier selection. The earliest research supplier evaluated Dickson, who obtained 23 supplier performance evaluation criteria by analyzing the survey results of purchasing agents and purchasing managers [1].Kannan et al. (2014) used fuzzy TOPSIS to solve the problem of green supplier selection, and applied three types of fuzzy TOPSIS methods to sort green suppliers [2].Luo Xinxing and Peng Suhua (2011) proposed a multi-level supplier evaluation selection model, first using AHP to determine the weight, and then using TOPSIS for supply evaluation selection [3].Li Deqing et al. (2011) applied AHP to evaluate and select green suppliers [4].Guo Bin et al. proposed the green supplier selection method of ANP-TOPSIS [5].

This paper combines the AHP and TOPSIS evaluation model methods to avoid the defects of the single method, effectively combine the advantages of the two methods, and improve its accuracy and scientific degree. Through case analysis and calculus, enterprises can more comprehensively control and choose to manage green suppliers.

\section{RELATED THEORY}

\section{A. AHP Related Theory}

AHP is a decision to decompose the relevant elements of decision-making problems into goals, criteria, programs, etc., objectively quantify human subjective judgments with a certain scale, and conduct qualitative and quantitative analysis on this basis. method. It hierarchically and quantifies the human mind process and uses mathematics to provide a quantitative basis for analysis, decision making, forecasting or control. However, it is difficult to guarantee the objectivity of the results and the effectiveness of the evaluation indicators is insufficient by the AHP method alone.

\section{B. TOPSIS Related Theory}

TOPSIS is an effective group decision making method that was first proposed in 1981 by Huang Qinglai for multiple indicators with limited solutions. The basic idea of the method is to calculate the distance between the finite solution point and the positive and negative ideal solution by using the Euclidean distance, and then calculate the closeness of each solution with the positive and negative ideal values, and obtain the relative closeness of each solution to the positive ideal solution. Degree, and sort according to its size, that is, the greater the closeness, the better the scheme[6].Compared with other similar methods, the TOPSIS method is relatively simple to calculate, the results are quantitative and objective, and the application is flexible. However, the TOPSIS method also has certain limitations. It has many calculation steps when calculating the normalization matrix, and the process of finding the ideal solution and the negative ideal solution is more complicated.

\section{The need for integration of AHP and TOPSIS}

The single use of AHP or TOPSIS methods has its inherent flaws. In order to obtain more accurate and scientific results for the lack of a single method of customer service, the paper combines the TOPSIS method with the AHP method to combine the advantages of both and to complement each other. The comprehensive evaluation model of AHP and TOPSIS can effectively solve the problem that it is difficult to assign weights due to too many indicators in the green supplier selection process, and can avoid the decision errors caused by one-sidedness and subjective factors, and improve the evaluation method while ensuring easy operation. The accuracy of the evaluation results. 


\section{AHP AND TOPSIS COMPREHENSIVE EVALUATION MODEl CALCULATION STEPS}

A. Determine the comprehensive weight of each indicator by $A H P$

Step 1, construct a hierarchical analysis structure:

The elements of the same level serve as the criterion. It dominates the next level of elements, and it is dominated by the elements of the previous level. The highest level has only one element, which represents the goal that the decision maker wants to achieve; the intermediate level is generally the criterion, the sub-criteria, which indicates the criterion for measuring whether the goal is achieved; the lowest level indicates the various measures, decisions, and solutions to solve the problem. Wait.

Step 2: Construct a judgment matrix:

Compare the relative weights of the $\mathrm{i}$-th element and the $\mathrm{j}$ th element from the second layer of the hierarchy model $\partial_{i j}$,For $\mathrm{n}$ elements, we get a pairwise comparison judgment matrix $A=\left(\partial_{i j}\right)_{n \times n}$. The values of $\partial_{i j}$ in the pairwise comparison matrix are generally assigned according to the following commonly used 1-9 scale method. The range of $\partial_{i j}$ is 1-9 and its reciprocal.

TABLE I JUDGMENT OF MATRIX SCALE AND ITS MEANING

\begin{tabular}{|c|l|}
\hline$\partial_{i j}$ assignment & Importance level \\
\hline 1 & i is as important as $\mathrm{j}$ \\
\hline 3 & $\mathrm{i}$ is slightly more important than $\mathrm{j}$ \\
\hline 5 & $\mathrm{i}$ is more important than $\mathrm{j}$ \\
\hline 7 & $\mathrm{i}$ is strongly important than $\mathrm{j}$ \\
\hline 9 & $\mathrm{i}$ is extremely important than $\mathrm{j}$ \\
\hline $1 / 3$ & $\mathrm{i}$ is slightly less important than $\mathrm{j}$ \\
\hline $1 / 5$ & $\mathrm{i}$ is obviously not important than $\mathrm{j}$ \\
\hline $1 / 7$ & $\mathrm{i}$ is not important to $\mathrm{j}$ \\
\hline $1 / 9$ & $\mathrm{i}$ is extremely unimportant than $\mathrm{j}$ \\
\hline
\end{tabular}

Step 3, calculate the weight and do the consistency test:

In order to ensure that the conclusions obtained by the application of AHP analysis are reasonable, it is necessary to conduct consistency check on the constructed judgment matrix This type of inspection is usually performed in conjunction with a sorting step.

Find the feature vector $\bar{\omega}$, Then, the maximum eigenvalue is obtained according to the formula

$$
\lambda_{\max }=\sum_{i=1}^{n} \frac{(A W)_{i}}{n W_{i}}
$$

The process of consistency check is as follows:

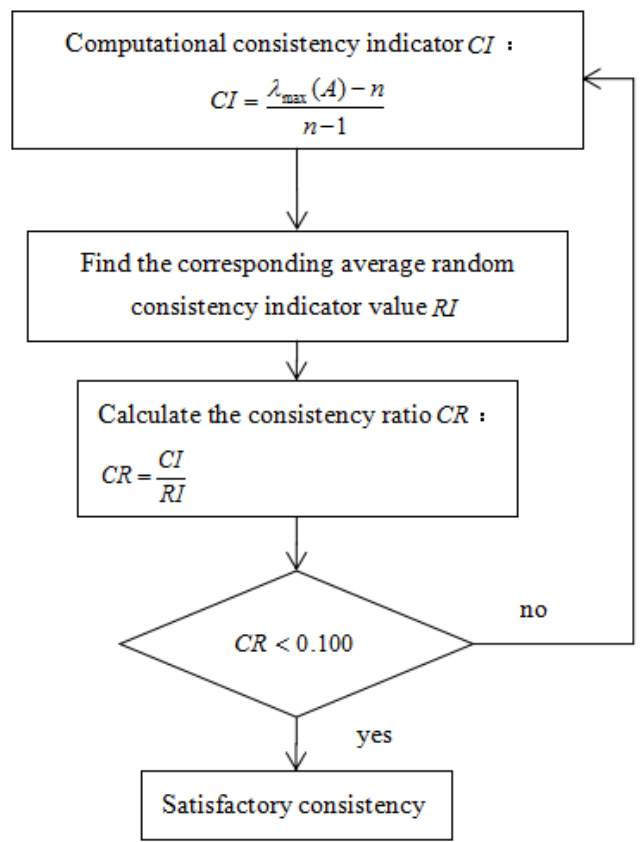

Fig 1. Flow Chart of Consistency Check

TABLE II AVERAGE RANDOM CONSISTENCY INDICATOR VALUES RI FOR DIFFERENT DIMENSIONS

\begin{tabular}{|l|l|l|l|l|l|l|l|l|l|}
\hline $\mathbf{n}$ & 1 & 2 & 3 & 4 & 5 & 6 & 7 & 8 & 9 \\
\hline $\mathbf{R I}$ & 0 & 0 & 0.58 & 0.90 & 1.12 & 1.24 & 1.32 & 1.41 & 1.45 \\
\hline
\end{tabular}

Step 4: Calculate the comprehensive weight of each level element for the system target as the weight coefficient of the TOPSIS evaluation:

After the above operation, a weight vector of a set of elements to an element above it can be obtained. In the next step, by combining the weights under the single criterion, the ranking weights of the schemes in the lowest layer for the total target are obtained, and the corresponding consistency ratio $\mathrm{CR}<0.10$ is ensured, which is used as the weight coefficient of the TOPSIS evaluation.

\section{B. Comprehensive evaluation and selection by TOPSIS}

- Step 1, normalize the matrix using the formula $Z_{i j}=\frac{y_{i j}}{\sqrt{\sum_{i=1}^{m} y_{i j}^{2}}}$
$z=\left(z_{i j}\right)_{m \times n}$. to obtain a normalized matrix

- Step 2, constructing a weighted normative decision matrix $M=W_{i} \times Z_{i j}$ by the comprehensive weight calculated by AHP, where $W_{i}$ represents the comprehensive weight coefficient obtained by AHP analysis.

- Step 3, determining the positive ideal solution L+ and the negative ideal solution $\mathrm{L}^{-}$of the evaluated object: 
- Positiveideal solution $L^{+}=\left\{\begin{array}{l}\max m i j-\text { Benefit type } \\ \min m_{i j}-\text { Cost type }\end{array}\right.$ Negative ideal solution $L^{-}=\left\{\begin{array}{l}\min m_{i j}-\text { Benefit type } \\ \max m_{i j} \text {-Cost type }\end{array}\right.$

- In step 4 , the distances of the evaluated objects relative to the positive and negative ideal solutions are respectively:

- $D^{+}=\sqrt{\sum_{j=1}^{n} W_{j}\left(\partial i j^{+}-\partial i j\right)^{2}}, D^{-}=\sqrt{\sum_{j=1}^{n} W_{j}\left(\partial i j^{-}-\partial i j\right)^{2}}$

- Step 5, calculate the relative closeness and determine the supplier. The relative closeness of each scheme to the positive and negative ideal solutions is:

- $C=\frac{D^{-}}{D^{+}+D^{-}}$

- The size of the $\mathrm{C}$ value is sorted, and the closer to 1 , the better the scheme $(0<\mathrm{C}<1)$.

\section{CASE STUDY}

W company introduces a green supply chain management model. At present, W Company is preparing to select one of the four suppliers to provide a certain part of solar energy. Take W company as an example, use AHP and TOPSIS comprehensive evaluation model to select the appropriate green supplier.

\section{A. Weight calculation.}

1) Construction of evaluation index system.

According to the specific situation of W company, construct a green supplier evaluation index system consisting of three dimensions: product information, environmental friendliness and service level.

TABLE III GREEN SUPPLIER EVALUATION INDEX SYSTEM

\begin{tabular}{|c|c|c|}
\hline Target layer & Criteria layer & Indicator layer \\
\hline \multirow{9}{*}{$\begin{array}{l}\quad \text { Green } \\
\text { Supplier } \\
\text { Evaluation A }\end{array}$} & \multirow{3}{*}{$\begin{array}{l}\text { Product } \\
\text { Information } \\
\text { Factor } \mathrm{B}_{1}\end{array}$} & Product price $\mathrm{C}_{1}$ \\
\hline & & Product quality $\mathrm{C}_{2}$ \\
\hline & & Product qualification rate $\mathrm{C}_{3}$ \\
\hline & \multirow{3}{*}{$\begin{array}{l}\text { Environme } \\
\text { ntally friendly } \\
\text { factor } \mathrm{B}_{2}\end{array}$} & Energy consumption $\mathrm{C}_{4}$ \\
\hline & & Sustainability $\mathrm{C}_{5}$ \\
\hline & & Product green design $\mathrm{C}_{6}$ \\
\hline & \multirow{3}{*}{$\begin{array}{c}\text { Service } \\
\text { level factor } \mathrm{B}_{3}\end{array}$} & Supply capacity $\mathrm{C}_{7}$ \\
\hline & & After-sales maintenance level $\mathrm{C}_{8}$ \\
\hline & & Customer Satisfaction $\mathrm{C}_{9}$ \\
\hline
\end{tabular}

2) Construct a judgment matrix and do consistency check.

Use the 1-9 scale method to compare product information, environmental friendliness, and the relative importance of service levels. In this case, experts believe that environmentally friendly factors are superior to service level factors, service level factors are superior to product information factors, and A-B judgment matrix is obtained.
TABLE IV COMPARISON OF FACTOR IMPORTANCE

\begin{tabular}{|l|c|c|c|}
\hline $\mathbf{A}$ & $\mathbf{B}_{\mathbf{1}}$ & $\mathbf{B}_{\mathbf{2}}$ & $\mathbf{B}_{\mathbf{3}}$ \\
\hline $\mathbf{B}_{\mathbf{1}}$ & 1 & $1 / 5$ & $1 / 3$ \\
\hline $\mathbf{B}_{\mathbf{2}}$ & 5 & 1 & 3 \\
\hline $\mathbf{B}_{\mathbf{3}}$ & 3 & $1 / 3$ & 1 \\
\hline
\end{tabular}

Calculate the product of each row element of the judgment matrix $M_{i}$ :

$$
M_{i}=\prod_{j=1}^{n} \partial i j, M_{1}=0.067, M_{2}=15, M_{3}=1
$$

Calculate the nth root $\bar{W}_{i}$ of $M_{i}$ :

$$
\bar{W}_{i}=\sqrt[n]{M_{i}}, \overline{W_{1}}=0.406, \bar{W}_{2}=2.446, \bar{W}_{3}=1
$$

Normalize the vector $\bar{W}=\left[\bar{W}_{1}, \bar{W}_{2}, \ldots, \bar{W}_{n}\right]^{T}$ (normalized):

$$
W_{i}=\frac{\bar{W}_{i}}{\sum_{j=1}^{n} \bar{W}_{j}}, W_{1}=0.105, W_{2}=0.637, W_{3}=0.258
$$

That is, the weight coefficient $\mathrm{W}=(0.105,0.637,0.258)$.

Calculate the largest eigenvalue of the judgment matrix:

$$
\lambda_{\max }=\sum_{i=1}^{n} \frac{(A W)_{i}}{n W_{i}}=3.039
$$

Consistency test:

$C I=\frac{\lambda_{\max }-n}{n-1}=\frac{3.309-3}{3-1}=0.019$, Look up table $R I=0.58$,

get $C R=\frac{C I}{R I}=0.033<0.1$.

It can be seen that the judgment matrix has good consistency.

In the same way, the following three matrices are obtained:

TABLE V B1-C JUDGMENT MATRIX

\begin{tabular}{|l|l|l|l|l|}
\hline B1 & C1 & C2 & C3 & \\
\hline C1 & 1 & 2 & 3 & 0.550 \\
\hline C2 & $1 / 2$ & 1 & $2 / 3$ & 0.210 \\
\hline C3 & $1 / 3$ & $3 / 2$ & 1 & 0.240 \\
\hline test & \multicolumn{4}{|l|}{$\lambda_{\max }=3.073, C R=0.063<0.1$} \\
\hline
\end{tabular}

TABLE VI B2-C JUDGMENT MATRIX

\begin{tabular}{|l|l|l|l|l|}
\hline B2 & C4 & C5 & C6 & \\
\hline C4 & 1 & $2 / 3$ & 2 & 0.333 \\
\hline C5 & $3 / 2$ & 1 & 3 & 0.500 \\
\hline C6 & $1 / 2$ & $1 / 3$ & 1 & 0.167 \\
\hline test & $\lambda_{\max }=3, C R=0<0.1$ & \\
\hline
\end{tabular}


TABLE VII B3-C JUDGMENT MATRIX

\begin{tabular}{|l|l|l|c|c|}
\hline B3 & C7 & C8 & C 9 & \\
\hline C7 & 1 & $2 / 3$ & 2 & 0.333 \\
\hline C8 & $3 / 2$ & 1 & 3 & 0.500 \\
\hline C9 & $1 / 2$ & $1 / 3$ & 1 & 0.167 \\
\hline test & \multicolumn{4}{|l}{$\lambda_{\max }=3, C R=0<0.1$} \\
\hline
\end{tabular}

3) Hierarchical total ordering.

TABLE VIII FACTOR LEVEL ANALYSIS

\begin{tabular}{|l|l|l|l|l|}
\hline & $\mathbf{B}_{\mathbf{1}} \mathbf{0 . 1 0 5}$ & $\mathbf{B}_{\mathbf{2}} \mathbf{0 . 6 3 7}$ & $\mathbf{B}_{\mathbf{3}} \mathbf{0 . 2 5 8}$ & $\mathbf{C}$-level total sort \\
\hline $\mathbf{C}_{\mathbf{1}}$ & 0.550 & & & 0.058 \\
\hline $\mathbf{C}_{\mathbf{2}}$ & 0.210 & & & 0.116 \\
\hline $\mathbf{C}_{\mathbf{3}}$ & 0.240 & & & 0.132 \\
\hline $\mathbf{C}_{\mathbf{4}}$ & & 0.333 & & 0.212 \\
\hline $\mathbf{C}_{\mathbf{5}}$ & & 0.550 & & 0.350 \\
\hline $\mathbf{C}_{\mathbf{6}}$ & & 0.167 & & 0.106 \\
\hline $\mathbf{C}_{\mathbf{7}}$ & & & 0.167 & 0.043 \\
\hline $\mathbf{C}_{\mathbf{8}}$ & & & 0.333 & 0.086 \\
\hline $\mathbf{C}_{\mathbf{9}}$ & & & 0.550 & 0.142 \\
\hline
\end{tabular}

This gives you a comprehensive weight:

$\mathrm{W}=(0.058,0.116,0.132,0.212,0.350,0.106,0.043,0.086,0.14$ 2 ), and use this as the weighting factor of the TOPSIS evaluation.

\section{B. Evaluation and selection}

According to the results of the W company's professional scores, the four candidate suppliers evaluate the indicator values as follows:

TABLE IX CANDIDATE SUPPLIER EVALUATION INDICATOR VALUES

\begin{tabular}{|l|l|l|l|l|l|l|l|l|l|}
\hline & $\mathbf{C}_{\boldsymbol{1}}$ & $\mathbf{C}_{\boldsymbol{2}}$ & $\mathbf{C}_{\boldsymbol{3}}$ & $\mathbf{C}_{\boldsymbol{4}}$ & $\mathbf{C}_{\boldsymbol{5}}$ & $\mathbf{C}_{\boldsymbol{6}}$ & $\mathbf{C}_{\mathbf{7}}$ & $\mathbf{C}_{\boldsymbol{8}}$ & $\mathbf{C}_{\boldsymbol{9}}$ \\
\hline $\mathbf{S}_{\mathbf{1}}$ & 140 & 0.86 & 0.91 & 830 & 0.41 & 0.21 & 0.88 & 0.75 & 0.78 \\
\hline $\mathbf{S}_{\mathbf{2}}$ & 110 & 0.80 & 0.79 & 705 & 0.45 & 0.42 & 0.91 & 0.63 & 0.83 \\
\hline $\mathbf{S}_{\mathbf{3}}$ & 180 & 0.90 & 0.93 & 789 & 0.30 & 0.39 & 0.89 & 0.75 & 0.74 \\
\hline $\mathbf{S}_{\mathbf{4}}$ & 100 & 0.93 & 0.85 & 608 & 0.65 & 0.26 & 0.85 & 0.70 & 0.71 \\
\hline
\end{tabular}

1) Indicator conversion.

Since the evaluation using the TOPSIS method requires the same trend for all indicators. In this case, except for the product price, energy consumption index and the evaluation results are inversely proportional, the rest are in a positive relationship. Therefore, the data of product price and energy consumption index are converged using the inverse method.
TABLE $X$ DATA CONVERGENCE OF PRODUCT PRICES AND ENERGY CONSUMPTION INDICATORS

\begin{tabular}{|l|l|l|l|l|l|l|l|l|l|}
\hline & $\mathbf{C}_{\mathbf{1}}$ & $\mathbf{C}_{\mathbf{2}}$ & $\mathbf{C}_{\mathbf{3}}$ & $\mathbf{C}_{\mathbf{4}}$ & $\mathbf{C}_{\mathbf{5}}$ & $\mathbf{C}_{\mathbf{6}}$ & $\mathbf{C}_{\mathbf{7}}$ & $\mathbf{C}_{\mathbf{8}}$ & $\mathbf{C}_{\mathbf{9}}$ \\
\hline $\mathbf{S}_{\mathbf{1}}$ & 0.007 & 0.86 & 0.91 & $\begin{array}{l}0.00 \\
12\end{array}$ & 0.41 & 0.21 & 0.88 & 0.75 & 0.78 \\
\hline $\mathbf{S}_{\mathbf{2}}$ & 0.009 & 0.80 & 0.79 & $\begin{array}{l}0.00 \\
14\end{array}$ & 0.45 & 0.42 & 0.91 & 0.63 & 0.83 \\
\hline $\mathbf{S}_{\mathbf{3}}$ & 0.006 & 0.90 & 0.93 & $\begin{array}{l}0.00 \\
13\end{array}$ & 0.30 & 0.39 & 0.89 & 0.75 & 0.74 \\
\hline $\mathbf{S}_{\mathbf{4}}$ & 0.01 & 0.93 & 0.85 & $\begin{array}{l}1.00 \\
16\end{array}$ & 0.65 & 0.26 & 0.85 & 0.70 & 0.71 \\
\hline
\end{tabular}

2) Normalized processing.

TABLE XI DATA NORMALIZATION PROCESSING MATRIX

\begin{tabular}{|l|l|l|l|l|l|l|l|l|}
\hline 0.429 & 0.492 & $\begin{array}{l}0.52 \\
2\end{array}$ & $\begin{array}{l}0.43 \\
4\end{array}$ & 0.436 & 0.317 & $\begin{array}{l}0.49 \\
8\end{array}$ & 0.529 & 0.509 \\
\hline 0.552 & 0.458 & $\begin{array}{l}0.45 \\
3\end{array}$ & $\begin{array}{l}0.50 \\
6\end{array}$ & 0.479 & 0.633 & $\begin{array}{l}0.51 \\
5\end{array}$ & 0.444 & 0.542 \\
\hline 0.378 & 0.515 & $\begin{array}{l}0.53 \\
3\end{array}$ & $\begin{array}{l}0.47 \\
0\end{array}$ & 0.319 & 0.588 & $\begin{array}{l}0.50 \\
4\end{array}$ & 0.529 & 0.483 \\
\hline 0.613 & 0.532 & $\begin{array}{l}0.48 \\
8\end{array}$ & $\begin{array}{l}0.57 \\
8\end{array}$ & 0.692 & 0.392 & $\begin{array}{l}0.48 \\
1\end{array}$ & 0.494 & 0.463 \\
\hline
\end{tabular}

3) Constructing a weighting matrix.

TABLE XII WEIGHTING MATRIX

\begin{tabular}{|l|l|l|l|l|l|l|l|l|}
\hline 0.02 & 0.05 & 0.06 & 0.09 & 0.15 & 0.03 & 0.02 & 0.045 & 0.07 \\
5 & 7 & 9 & 2 & 3 & 4 & 1 & \\
\hline 0.03 & 0.05 & 0.06 & 0.10 & 0.16 & 0.06 & 0.02 & 0.038 & 0.07 \\
2 & 3 & 0 & 7 & 8 & 7 & 2 & & 7 \\
\hline 0.02 & 0.06 & 0.07 & 0.10 & 0.11 & 0.06 & 0.02 & 0.045 & 0.06 \\
2 & 0 & 0 & 0 & 2 & 2 & 2 & & 9 \\
\hline 0.03 & 0.06 & 0.06 & 0.12 & 0.24 & 0.04 & 0.02 & 0.042 & 0.06 \\
6 & 2 & 4 & 3 & 2 & 2 & 1 & & 6 \\
\hline
\end{tabular}

4) Calculate the positive ideal solution and the negative ideal solution. This example is a benefit indicator.

Positive ideal solution

$\mathrm{L}^{+}=(0.036,0.062,0.070,0.123,0.242,0.067,0.022,0.045,0.077)$

Negative ideal solution

$\mathrm{L}^{-}=(0.022,0.053,0.060,0.092,0.112,0.034,0.021,0.038,0.066)$

5) Calculate the distance values and relative closeness of each solution to positive and negative ideal solutions.

TABLE XIII DISTANCE VALUES AND RELATIVE CLOSENESS OF EACH SOLUTION TO POSITIVE AND NEGATIVE IDEAL SOLUTIONS

\begin{tabular}{|c|c|c|c|}
\hline \multicolumn{4}{|c|}{$D^{+}=\sqrt{\sum_{j=1}^{n} W_{j}\left(\partial i j^{+}-\partial i j\right)^{2}} D^{-}=\sqrt{\sum_{j=1}^{n} W_{j}\left(\partial i j^{-}-\partial i j\right)^{2}} C=\frac{D^{-}}{D^{+}+D}$} \\
\hline $\mathbf{S}_{1}$ & 0.0557 & 0.0247 & 0.3072 \\
\hline $\mathbf{S}_{2}$ & 0.0447 & 0.0358 & 0.4447 \\
\hline $\mathbf{S}_{\mathbf{3}}$ & 0.0778 & 0.0110 & 0.1239 \\
\hline $\mathbf{S}_{4}$ & 0.0094 & 0.0784 & 0.8929 \\
\hline
\end{tabular}

6) Supplier sorting and selection.

According to the data in the above table, the order of the suppliers is $S_{4}>S_{2}>S_{1}>S_{3}$. The best is $S_{4}$, the worst $S_{3}$, so W company should give priority to $\mathrm{S}_{4}$ when choosing. 


\section{CONCLUSION}

This paper studies the selection and evaluation of W's green suppliers. The comprehensive evaluation model based on AHP and TOPSIS can effectively solve the problem that it is difficult to assign weights due to too many indicators in the process of green supplier selection, and can avoid the decision errors caused by one-sidedness and subjective factors, while ensuring that the evaluation method is easy to operate. Improve the accuracy and scientificity of the evaluation results.

\section{ACKNOWLEDGMENT}

On the occasion of the completion of this work, I would like to sincerely thank the Hui Hongqi teacher who cares and educates me. At the same time, I would like to thank all the experts who have reviewed this article. Please give us valuable comments and correct them.

\section{REFERENCES}

[1] Dickson. An Analysis of Vendor Selection Systems and Decisions[J].Journal of Purchasing,1996(2):28-41.

[2] Kannan D,Jabbour A.D.L.S,Jabbour C.J.C.Selecting green suppliers based on GSCM practices: Using fuzzy TOPSIS applied to a Brazilian electronics company[J].Eur.

[3] Luo Xinxing, Peng Suhua. Research on Supplier Evaluation and Selection Based on AHP and TOPSIS in Green Supply Chain[J].Soft science.2011(02):53-56. (In Chinese)

[4] Li Deqing. Application Research of Analytic Hierarchy Process in Evaluation and Selection of Green Suppliers[J].Journal of Kunming University of Science and Technology,2011,11(2):49-55. (In Chinese)

[5] Guo Bin, Liang Jiangping, Liu Yinping. Study on Supplier Evaluation and Selection Based on ANP-TOPSIS in Green Supply Chain Environment $[\mathrm{J}]$. Science and Technology Management Research, 2015(11):229-234. (In Chinese)

[6] James Freeman Tao Chen. Green supplier selection using an AHPEntropy-TOPSIS framework[J]. Supply Chain Management: An International Journal,2015(11).27-34. 